\title{
Introduction to the Collaboration Journey for Innovation
}

Innovation, collaboration and entrepreneurship are much needed in the period we are living in. We need to be creative, we need to think outside of the box, we need to go out of our comfort zone, and we need to surprise ourselves with new thinking and new ideas. The solution is not to continue doing the things the same way and then add a mobile app into the mix. No. Nowadays, we have the beautiful opportunity to re-think our way of living and working. And innovation offers techniques to help us properly re-think our lives creatively, to stop and to breathe, calm down and consider what kind of present we want to live in and what kind of future we want to have, which kind of values we have now and want to continue to have. We are in a period of change, and for this period we need both leadership and creativity, we need innovation, we need positive thinking, we need innovative thinking, and we need collaborative thinking. In this book, I merged innovation with leadership, innovation with emotional intelligence, collaboration with competition, cost with knowledge, artificial intelligence with emotional intelligence, and collaboration with innovation. We need fresh ideas, we need business leaders who can execute these fresh ideas, and we need leaders who can drive our industry and our society as a whole towards this change.

\section{Decentralization of knowledge and innovation}

I have seen that knowledge is centralized and hidden in remote places both virtually and physically. The question is: How accurate and specific is the knowledge that we need to collaborate and work together to make innovation happen? Innovation might be coming from one idea or concept, maybe from a research result, and putting in the effort to make it become reality, or even still developing it before reaching the market, is not an individual effort, it's a community effort.

But the first step is to find with whom we will make this step. And understanding this decentralization is critical to realizing that there are infinite options to collaborate and to innovate together, faster. It is essential to trust people when working remotely because success is all about creating relationships.

\section{Collaboration over competition}

The Covid-19 pandemic and ensuing economic crisis are highlighting the importance of collaboration to solve global challenges, but also get to the core of what competition and collaboration really are. If you enhance support for collaboration, 
then competitiveness decreases; otherwise, you reduce the chances of being competent. It seems that it is time to revisit the concept of competition

The concept of competition is different depending on whether we are talking about the field of innovation and entrepreneurship or basing our debate on the field of economics in general. But in any case, the paradox of collaboration as opposed to competition is quite interesting. On the one hand, you have the perspective of competition when there is scarcity of resources. This is the case for innovation and entrepreneurship, as can be witnessed from the fact that you are in a position to innovate better in times of crisis, and the same principle goes when choosing for entrepreneurship, starting from nothing, typically with great scarcity and no external support.

On the other hand, collaboration is happening in the face of scarcity, when trying to survive as a small group inside a bigger industry, or when a group of companies collaborate to achieve a goal within an industry. If you ask an economist, competition comes from abundance. And again, you could argue that in innovation, knowledge is infinite and the way that you as a leader can compete is to mobilize resources, but this mobilization of resources is, in the end, collaboration.

\section{Digitalization}

Digitalization is not simply doing "the same thing, but online", it's being creative when re-thinking how we are doing things. We have to surprise, we have to create new ways of working, new ways of hosting events, new ways of meeting. It's about people, not so much about technology; also, it is about creativity, about having an open mind to think and create different solutions. And this is also what innovation is all about: using your creativity to be able to create a new present. As you might know, digital transformation and digitalization of processes is not about technology, gadgets or tools, it's more about people and common sense. And also, digitalization is how we can better leverage the technology to help us in our businesses, daily work and daily life.

\section{Collaborative innovation}

Collaborating for innovation is an activity that can comprise co-brainstorming, cocreation, co-designing, co-researching, co-developing, co-prototyping, co-implementing, co-executing, co-going-to-market, co-adopting with experts, academics, startups, investors and other types of partners you can imagine in your value chain and ecosystem. Innovation cannot be done alone. You might need to collaborate with academics to understand some parts of your idea, technology or concept, or maybe you need to know who can produce your new product, so you have to be an active part of your 
industry and of the ecosystem you are in. Make connections and collaborate. This is the fastest and strongest choice you can make for your business to create growth. Collaboration for innovation means that you might be making a change to how current factories are producing your new product, or how companies work together, and this is innovation too. You are innovating on two levels: one is your innovative solution, and the other is that you innovate in the process. For instance, you are innovating your whole value chain from practical to transformative.

\section{Collaboration journey}

The collaboration journey is the structure, a transparent and clear process that shows which phase you are in in the course of a collaboration. It gives you a guide to what you have to do in each phase, which contracts are needed, which information is required and how to communicate to be able to go to the next phase. Since we are talking about innovation, we are dealing with the subjects of uncertainty, risk and trust. You can only succeed if you are transparent, clear, honest and every "collaborator" knows the current phase, and what information is needed. In Chapter 3 of this book, you will find Figure 3.4 detailing the "collaboration journey", with the steps from "searching phase" to "collaboration phase", and Figure 3.6 showing the "collaboration canvas", a clear framework that you can follow to know which information is important to think about and discuss with your collaborator.

\section{Emotional intelligence}

Emotions are valuable information for businesses, innovation, collaboration and entrepreneurship, not only for life or for learning. Emotions are relevant, even more relevant after having lived through a global pandemic, where a strong set of emotions came upon us in form of fear, disappointment, frustration, stress, sadness or relief, calm, joy and happiness. Emotions are information and our drivers in decision making, creativity, communication and productivity.

How much we are aware of them, and how much we are aware of the emotions of others, is the key to success in our professional and personal lives. It is very obvious that there are options to act on fear and make decisions based on that fear and panic or to calm down and understand the fear and translate this fear into positive action.

In this book, I am applying emotional intelligence for innovation, collaborations, entrepreneurship, leadership, selling innovation and creation of innovation ecosystems and communities. 


\section{Cost of knowledge}

We are always talking about how to create trust, about how to communicate better, and about the worry of "talking about money". In this "all free society" where you can consume content for free on the internet everywhere, we are too used to getting free knowledge. This is creating a place where paying for knowledge or paying for co-creation is not seen as positive. In this book, you will find a different perspective, because talking about money, costs, incomes, commission fees, risks and ratios per hour is creating trust, transparency, understanding, respect and recognition of each other's value and how you create value together. Because knowledge is intangible, knowledge needs to be framed in such a way that it is possible to value it. The way to avoid anxieties about taking on budgeting, finance, tax and other financial obligations is to take action, to do calculations and to talk about the cost of doing innovation and sharing knowledge in a transparent way.

\section{Innovation leadership}

It seems it is seldom recognized that the style of leadership which is required to drive innovation is very specific, sometimes labeled "transformational leadership", "kind leadership", "feminine leadership", or "simple leadership". The levels of influence and social intelligence needed to drive change and mobilize resources, for which you might not have full responsibility, is hard and requires high levels of self-esteem, self-confidence, kindness, drive, courage, respect, learning, active listening, passion, honesty, transparency, positivity, curiosity and resilience. This is a type of leadership that has to be understood well by C-level executives, governments and entrepreneurs. Innovation leadership is embedded across corporations, SMEs, startups, governments and investors. It is a way to drive change to make innovation happen in the field with the collaboration of the whole ecosystem.

\section{Positive impact}

Taking a $360^{\circ}$ perspective of your impact, at whose lives you are touching, we all have to accept other benefits and other effects of our actions, outside pure financial profit. This is a question that many social impact investors are asking of entrepreneurs as well - it isn't only a corporate concern. And it's difficult to answer. I remember asking an investment manager directly about how to assess impact, and she said, well, you look at the sustainable development goals. Well, this is not enough, and this is not a good answer. You can use the sustainable development goals (SDG) for doing the first categorization, to use it as a language everyone will understand. But then you have to look at your value chain, at your supply chain, at 
your customers, at your local area, region, country and at your industry as a whole and see if you are making a change in the behavior, market, way of working, way of operating, way of producing, way of buying, etc. Hence, apparently, we are all learning this journey of assessing impact and we have to know this - we are learning, and we can learn from those who researched this topic many years ago and re-learn and colearn with them again because our society has changed. Then, you analyze whether this change is positive and brings a benefit and value to these actors. It is very useful as well to look at the philosophical question: What kind of future do you want to have? 
